\title{
The Divine Light and Ecstasy in Religious and Near-Death Experiences: A Retrospective Glance and a View for the Future
}

\author{
Brian A. Bain, M.A. \\ Brentwood Bay, BC
}

\begin{abstract}
Throughout history and across cultures, certain aspects of religious mysticism bear striking resemblance to modern near-death experiences (NDEs). Interpretations of these experiences vary widely, but the descriptions of the experiences themselves can be very similar, and are very difficult to discount as mere coincidence. While modern science has attempted to understand NDEs in various ways, it has yet to delve deeply into its role as part of a continuum of human experience. NDEs can be viewed as the latest stage in a long history of a phenomenon that transcends cultural and temporal boundaries. By focusing on where such profound human experience shares common ground, we will be able to see humanity itself at perhaps its most sublime level.
\end{abstract}

KEY WORDS: near-death experience; mystical experience; religious studies; comparative religion.

The human encounter with divine light and the ecstasy surrounding that encounter have been well documented. The major religions of the world have all recorded numerous accounts of this phenomenon. In the Western world today we find the same experience being reported by people who have undergone near-death experiences (NDEs). This

Brian A. Bain completed his B.A. and M.A. in Religious Studies at the University of British Columbia. Presently he is a freelance researcher in the field of spiritual experiences, with special interest in the relationship between near-death experiences and religious experiences in various historical traditions. Reprint requests should be addressed to Mr. Bain at 1005 Win Way, Brentwood Bay, BC, Canada V8M 1E7; e-mail: bainbl@shaw.ca. 
provides us with a new foundation for approaching the subject of human spirituality: we find an experience that is common to people who are from entirely different cultures, and can be found throughout history.

It is almost regrettable that the word mysticism has been chosen to apply to the form of spiritual expression that I am about to describe. It evokes - as the root of the word suggests - something mysterious, even weird. In fact I am talking simply about an experience, an awesome experience to be sure, but one that has often been felt by perfectly normal, ordinary, rational people.

Classically, mysticism has been used to describe a direct experience, or even union, with God. God does not mean the same thing to everyone in every culture, however. He may be a she; personal or impersonal; outside of us or inside of us; or the whole concept can get so abstract that the word God cannot apply at all. While there is no single term to accommodate all definitions, I will use the term Divine here as being preferable to contrived jargon or no terminology at all.

While the mystical experience often takes on different forms, it is generally regarded as an area of commonality in the field of comparative religion. The mysticism that $I$ am about to examine here makes this abundantly clear. We frequently see instances of communion, or even complete unity with the Divine. Most significantly, the language used to describe the mystical experience of light and ecstasy across religious traditions is almost exactly the same as that used to report the same encounter in near-death experiences.

The $20^{\text {th }}$ century has witnessed a proliferation of accounts of experiences with a super brilliant "living light," usually associated with feelings of ecstatic joy. At the beginning of the $20^{\text {th }}$ century, Richard Maurice Bucke (1901) published an intriguing work entitled Cosmic Consciousness: A Study in the Evolution of the Human Mind. Bucke argued that experiences of "Illumination," far from being a symptom of mental instability, were in fact a feature of highly evolved human minds. Bucke himself had had such an experience:

All at once, without warning of any kind, [Bucke] found himself wrapped around, as it were, by a flame-colored cloud. For an instant he thought of fire - some sudden conflagration in the great city. The next (instant) he knew that the light was within himself.

Directly after there came upon him a sense of exultation, of immense joyousness, accompanied or immediately followed by an intellectual illumination almost impossible to describe. Into his brain streamed one momentary lightning-flash of the Brahmic Splendor which has ever since lightened his life. Upon his heart fell one drop of the Brahmic Bliss, leaving thenceforward for always an aftertaste of 
Heaven. (George Moreby Acklom's introduction: "The Man and the Book," unnumbered page, in Bucke, 1901)

Bucke went on to interview 50 or so others that he had run across who had had similar experiences. One was the case of "C.M.C.," who had this to say about her experience:

It was the gladness and rapture of love, so intensified that it became an ocean of living, palpitating light, the brightness of which outshone the brightness of the sun. Its glow, warmth and tenderness filling the universe. (Bucke, 1901, p. 328)

The experience of "C.M.C." was typical of those whom Bucke had interviewed. He went on to surmise that this is a feature of a late stage of human evolution. This latter claim might be doubtful; one look at the ancient texts described in the pages to follow show that such experiences were reported often in the past. However, the breadth and clarity of people's profound spiritual experiences in the $20^{\text {th }}$ century, both within and outside of traditional religious bounds, set off Bucke's work as a pioneering effort.

Shortly after Bucke's work, William James published his now classic Varieties of Religious Experience (1902). In this work, James acknowledged the pioneering effort of Bucke. He went on to describe the many and various kinds of religious experience. James confirmed the modern day persistence of the type of encounter that Bucke had focused on. As an example, James drew upon the autobiography of a man called "J. Trevor":

... suddenly, without warning, I felt that I was in Heaven - an inward state of peace and joy and assurance indescribably intense, accompanied with a sense of being bathed in a warm glow of light ....

... When [experiences such as this] came, I was living the fullest, strongest, sanest, deepest life .... I was aware that I was immersed in the infinite ocean of God. (James, 1902, pp. 388-389)

Remarkably similar to these accounts, but in ever-increasing numbers in recent years, are those found in near-death experiences. In 1975, Raymond Moody published his ground-breaking account of these occurrences in Life After Life. In this work, Moody accumulated some 150 interviews of people who had been pronounced clinically dead, but had been resuscitated and lived to tell what happened to them on "the other side." While the accounts do vary somewhat, the similarities are most remarkable. Typical is the experience of a patient who was hospitalized for a severe kidney condition, and had lapsed into coma:

During this period when I was unconscious, I felt as though I were lifted right up, just as though I didn't have a physical body at all. 
A brilliant white light appeared to me. The light was so bright that I could not see through it, but going into its presence was so calming and so wonderful. There is just no experience on earth like it. (Moody, 1975, p. 75)

A proliferation of personal accounts of this kind of experience, as well as scientific studies of the phenomenon, followed Moody's book. Among the more noteworthy in the latter category include Kenneth Ring's Life at Death: A Scientific Investigation of the Near-Death Experience (1980). After having interviewed more than 100 people who had had the experience under investigation, Ring was able to confirm most of Moody's findings, and was able to eliminate such considerations as religious background as a determining factor in what people experienced. In fact, Ring concluded, reports of near-death experiences remain remarkably similar regardless of the person's upbringing.

A decade later came Melvin Morse's Closer to the Light (Morse and Perry, 1990). Morse examined some near-death experiences of children in order to see if there were any significant differences between these reports and their adult counterparts. Children were good subjects because they had not had time to absorb many adult conceptions about death. Typical of these is the story of "Bill," who at the age of nine had accidentally inhaled gasoline, and was suffocating:

All of a sudden I couldn't move. I found myself floating into a dark tunnel. I saw light and the closer I floated to it, the more I liked it. When I got to the portal opening to the Light and was just ready to step through, I felt a combination of relief, joy, and pleasure. I just wanted to be inside the Light. (Morse and Perry, 1990, p. 169)

Morse also concluded that reports of near-death experiences are for the most part stable and consistent, whether recounted by children or adults.

Personal accounts of the near-death phenomenon continue to enjoy wide circulation. Not the least of these was Betty Eadie's 1994 bestseller, Embraced by the Light (Eadie and Taylor, 1992). Eadie wrote of her own near-death experience, which turned out to be considerably more detailed than other reports. The core experience immediately following "death," however, was still quite typical. In a hospital for surgery, Eadie found herself becoming weaker and weaker. After hearing a "soft buzzing sound" (Eadie and Taylor, 1992, p. 29) she felt herself leave her physical body. A deep darkness surrounded her, and she felt herself moving forward through it. A "pinpoint of light" (p. 40) appeared in the distance. Getting closer, this light, "far more brilliant than the sun" (p. 40), had the figure of a man in it. Next, 
I saw that the light immediately around him was golden .... I felt his light blending into mine, literally, and I felt my light being drawn to his .... And as our lights merged, I felt as if I had stepped into his countenance, and I felt an utter explosion of love. (Eadie and Taylor, $1992, \mathrm{p}, 41)$

Eadie identified this light with Jesus, and went on to describe a moving account of her life "after death," as well as events in her life following recovery.

Another bestseller in the same category was Dannion Brinkley's Saved by the Light (Brinkley and Perry, 1994). Having been struck by lightning, Brinkley experienced a classic near-death episode. He left his physical body, and looked at himself being slid into the ambulance. The medical technician pronounced him "gone," and he saw the eye of a tunnel approaching toward him. The tunnel eventually engulfed him completely, and he heard

the intensely beautiful sound of seven chimes ringing in rhythmic succession.

I looked ahead into the darkness. There was a light up there, and I began to move toward it as quickly as possible .... Ahead the light became brighter and brighter until it overtook the darkness and left me standing in a paradise of brilliant light. This was the brightest light I had ever seen ....

... It was as though I were seeing a lover, mother, and best friend, multiplied a thousandfold. As the Being of Light came closer, these feelings of love intensified until they became almost too pleasurable to withstand. (Brinkley and Perry, 1994, pp. 8-9)

Brinkley went on to describe how he gained some remarkable psychic abilities after his "return," including the ability to foretell certain future events, and that he remarkably had a second near-death experience during an operation that was supposed to mend a heart weakened by the lightning strike.

Brinkley followed up with a second book, entitled At Peace in the Light (Brinkley and Perry, 1995), in which he reported that he continued to have psychic episodes, such as foretelling major world events. Very interesting in relation to his own near-death experience was Brinkley's account of Bill Wilson, co-founder of Alcoholics Anonymous. Wilson was reported to have had a mystical experience, without having been near death at all. Brinkley quoted Wilson's account of his experience as follows:

Suddenly, my room blazed with an indescribably white light.... I was seized with an ecstasy beyond description. Every joy I had known 
was pale by comparison. The light, the ecstasy - I was conscious of nothing else for a time. (Brinkley and Perry, 1995, p. 152)

The similarities between all of these reports are quite compelling. Indeed, descriptions of this kind have been made throughout history and across cultural boundaries. These kinds of experiences are a core component of human spirituality, and can be found extensively in every major religious tradition in the world.

Several attempts, however brief, already have been made to compare these modern-era experiences with the historical encounter with Divine light and ecstasy in mystical religious writings. In Life After Life, Moody (1975) himself found some significant parallels, noting the vision of blinding light witnessed by St. Paul on the road to Damascus. Moody also made reference to The Tibetan Book of the Dead (Evans-Wentz, 1957/11 ${ }^{\text {th }}$ century), which offered counsel concerning the many things that we might encounter after death, including an encounter with a clear, pure light. Finally, Moody recounted the experiences of Emanuel Swedenborg, an $18^{\text {th }}$-century Swedish scientist. Swedenborg claimed that the soul survives bodily death, and described the "light of the Lord' which permeates the hereafter, a light of ineffable brightness," which Swedenborg himself had glimpsed (Moody, 1975, p. 126).

In a follow-up work entitled Reflections on Life After Life, Moody (1977) found more parallels. For example, the Venerable Bede, an $8^{\text {th }}$. century English monk, told the story of a man who had a near-death experience. After several interesting encounters, the "dead" man came across a clear, bright light. So bright was this light that it seemed "greater than the brightness of daylight, or the sun's rays at noon" (Sherley-Price, 1968, pp. 289-293). Moody also made reference to Leo Tolstoy's The Death of Ivan Ilyich (1981/1886), which described the death scene of Ilyich in terms of being in a dark, cavelike space; of having a flashback of his past life; and at last, of entering into a brilliant light.

Frederick Holck drew some interesting parallels between near-death and mystical religious experiences. Holck added to Moody's reading of The Tibetan Book of the Dead that the "nonphysical existence is to the knowing one blissful consciousness in its purest form" (Holck, 1978-79, p. 4). In the same vein, in Zoroastrianism, a dead person is said to experience as much joy in three days as one would normally experience in a lifetime. Holck also pointed out that Plato's myth of Er made reference to a brilliant, pure light. Moreover, such references are not restricted to 
near-death experiences: Hinduism's Bhägavata Purāna tells a story of a couple who, praying for Divine help, fell unconscious, and "a light suddenly flashed" (Holck, 1978-79, p. 8). In the Jewish extracanonical tradition, we read of a "radiant light" in the Apocalypse of Abraham, and the "immeasurable light in heaven" in the Book of the Secrets of Enoch and the Testament of the Twelve Patriarchs. In Buddhism's Saddharmasmrityupasthāna Sütra, we find that when someone approaches death, "he sees a bright light, and being unaccustomed to it at the time of his death he is perplexed and confused." (Holck, 1978-79, p. 8).

Carol Zaleski (1987) has found similar parallels in the medieval Christian tradition. When it comes to visions of Divine light, both Gregory the Great's Dialogues and Dante's Paradiso contained descriptions of an "illuminated unifying vision" (Zaleski, 1987, p. 125). While reserving judgment on the validity of near-death accounts, Zaleski acknowledged that the medieval accounts that she examined bore "a striking resemblance" to the modern near-death encounter with a Divine Light (Zaleski, 1987, p. 125).

The parallels drawn to date between modern day and more classic encounters with the light Divine and its unsurpassed joy are quite valid. However, most authors began by drawing broad similarities between the near-death experience in general and comparing that with religious writings. When we narrow the focus to see what happens when we compare the actual encounter with Divine light and ecstasy in near-death experiences with similar reports in the mystical teachings of the world's major religious traditions, the volume, depth, and breadth of the similarities is compelling.

The most exciting result of this comparison is the commonality of language that is used to describe the Divine encounter. Even across cultures, throughout time, and with the imperfections of translation, we find strikingly similar words being used to tell us what such an experience is like. While descriptions of God, "the gods," or Ultimate Truth vary wildly from tradition to tradition, we now have a "thread that binds" not only the major religions of the world, but also nonreligious spiritual experiences.

The human spiritual encounter with light and ecstasy is also deeply meaningful. It has given lasting new meaning to countless people worldwide and throughout history. Recognizing this as a fundamental aspect of human spirituality may help bind humanity together, rather than set groups apart. For the individual, the realization of this kind of spiritual knowledge can bring about a depth of feeling that would otherwise be beyond our wildest imagination. 


\section{Near-Death Experiences in Retrospect}

Scientists and academics have not generally accepted the neardeath experience as an encounter with the Divine by a "soul" that survives death. In fact, a fairly extensive critical literature has developed contending the contrary, though not all the critics agree on what the cause of the experience might be. Theories range from the influence of an unusual flow of brain chemicals; to the reaction of the dying brain to reduced levels of oxygen; or to purely psychological factors such as dreams, hallucinations, or wish fulfillment. While all of these criticisms offer interesting possibilities, none of them rise above the level of speculation. In short, the critics have no better claim to what the experience really means than anyone else.

Still, critics have raised many points that are well worth considering. One possibility is that the experience could be induced by the influence of drugs. As Aldous Huxley first wrote in 1954, drugs such as mescaline can induce mystical states very similar to the ones that are under investigation. In The Doors of Perception and Heaven and Hell, Huxley wrote:

What are the common features which this pattern imposes upon our visionary experiences? First and most important is the experience of light. Everything seen by those who visit the mind's antipodes is brilliantly illuminated and seems to shine from within. All colours are intensified to a pitch far beyond anything seen in the normal state, and at the same time the mind's capacity for recognizing fine distinctions of tone and hue is notably heightened. (Huxley, 1954, p. 89)

Huxley's observations led, in part, to the 1960s drug culture. Wellknown authors and respectable academic researchers investigated the validity of drug-induced mystical experiences. In 1966, Walter Pahnke and William Richards found that lysergic acid diethylamide (LSD) could produce experiences that corresponded to the essential categories found in the literature dealing with mysticism. These included unity, changes in one's perception of objectivity and reality, transcendence, sacredness, paradoxicality, ineffability, transience, a very positive mood, and positive changes in attitude and behavior. Similarly, Alan Watts (1973), Huston Smith (1964), Stanislav Grof (1972), and Ring (1988) concluded that psychedelic drugs such as mescaline, LSD, and psilocybin were capable of inducing mystical experiences.

Further, psychedelic drugs seemed to be able to induce NDEs or something very much like an NDE. Ronald Siegel (1980) found that phencyclidine (PCP) could induce an experience very much like an 
NDE, including images of tunnels and lights, out-of-body states, spirit guides, and a life review. Siegel concluded that NDEs were some form of hallucination that uses images already stored in the brain. Similarly, Jack Provonsha (1981) found similarities between NDEs, experiences induced by psychedelic drugs, and carbon dioxide toxicity. Provonsha asked rhetorically if NDEs are, by extension, really the work of psychochemicals. This would mean that the NDE is really an experience of the dying process, not death itself. Scott Rogo (1984), in the same vein, reviewed the literature on the parallels between NDEs and the effects of anesthetics, particularly ketamine. He concluded that while no direct causal link could be drawn between the two, the parallels were strong enough to cast doubt on purely metaphysical explanations of the NDE.

Interestingly, psychedelic drugs can even have some of the beneficial aftereffects of undergoing actual NDEs. Pahnke (1969) found that the majority of terminally ill cancer patients who were administered LSD benefited from the treatment. The aftereffects included lessened anxiety and depression, as well as a reduced fear of death. Richards, Grof, Louis Goodman, and Albert Kurland (1972) also concluded that, after having been administered LSD, one third of terminal cancer patients experienced dramatic improvement in outlook regarding their condition. Death was no longer regarded by these patients as an end to all personal existence, but rather "as a transition into a different type of existence" (Richards, Grof, Goodman, and Kurland, 1972, p. 146). Grof (1972-73) found similar, but even more positive results: 27 of 31 patients administered LSD showed improvements in the same areas noted by Pahnke, and those who had "peak" experiences such as unity, transcendence, and sacredness ended up having the most positive and lasting attitude changes of all.

By extension, some argued that the brain itself can manufacture chemicals that act very much like their artificial psychedelic counterparts. Daniel Carr $(1981,1982)$ argued that $\beta$-endorphins and similar brain chemicals that are released during the dying process might trigger the NDE. Even changes to blood pressure in the inner ear can produce the sensation of rising out of the body, floating away in space, and even near-death visions (Burt, 1968).

Several critics of the metaphysical model of the near-death experience have argued that levels of oxygen to the brain, which vary among people who are about to die, can trigger images commonly reported in NDEs. Richard Blacher (1979), in an early rebuttal to Moody's (1975) claim that the NDE may constitute evidence of the 
survival of bodily death, claimed that those who have had NDE-like experiences of the type that Moody described were likely suffering from hypoxia. Ernst Rodin (1980) claimed that NDEs were simply hallucinations or delusions caused by the deprivation of oxygen to the brain, based on his analysis of his own near-death experience.

Others have rebutted this brand of criticism. First, of course, not all of those who have had an NDE were under the influence of any drugs or anesthetics. Moreover, $\beta$-endorphins cannot in and of themselves account for the whole of the NDE, only perhaps the part dealing with feelings of well-being or ecstasy. Michael Sabom (1980b) took exception to Blacher's claims that NDEs result from hypoxia, on the grounds that persons suffering from oxygen deprivation typically end up with a confused and muddled memory, quite the opposite of the clarity found in the NDE. Further, Sabom (1980a) claimed that Rodin's personal experience was not an NDE at all. Ian Stevenson agreed with Sabom that oxygen deprivation to the brain typically induces a "toxic psychosis" characterized by confusion and mental obfuscation; but this is not at all the kind of report given by those who have had an NDE: rather, the latter "seldom, if ever ... have felt more alive, alert, and mentally clear" (Stevenson, 1980, p. 271).

Other critics have used psychological counterexplanations of the metaphysical model of the NDE. In another response to Rodin's article mentioned above, Nathan Schnaper (1980) supported Rodin's contention that NDEs are probably delusions or hallucinations. Schnaper extended Rodin's thesis, however, to include other possible sources for the experience. These included considerations of physiology, such as hypoxia or anoxia; pharmacology, such as ketamine and other anesthetics and pharmaceuticals; and psychology, such as dissociative reactions, panic, and psychosis. Schnaper concluded that the great public interest in the NDE phenomenon is best understood as death denial.

Ronald Siegel (1980) also contended that NDEs are hallucinations, brought about by psychological and neurophysiological factors, although he admitted that those processes are not yet fully understood. Like Schnaper, Siegel maintained that NDEs are a product of a human imagination longing for an afterlife. Jan Ehrenwald agreed: "most claims of apparent survival near death or after resuscitation result from a blend of hallucinatory wish fulfillment and massive denial of illness in terms of defensive maneuvers" (1978, $p$. 235). Russell Noyes (1979) concurred that NDE features such as depersonalization serve as a defense mechanism against the threat 
of death: the "life review" and other sweeping recollections, he wrote, are likely a result of the dying person attaching him- or herself to memories that will act as reminders of their own existence. Susan Blackmore (1988) added that while NDEs were indeed hallucinations, visions of a tunnel and/or a great light were most likely the result of activity in the visual cortex of a dying brain; survivors transform these images into objective concepts drawn from sensory experience.

Psychoanalysts have come up with additional possible explanations of the NDE phenomenon. According to Uri Lowental (1981), the bliss felt during an NDE is an infantile regression to the memory of the bliss felt under a mother's protection; the "dark tunnel" is a recollection of the mother's birth canal, and the "bright light" would be a memory of the mother's radiant face. Similarly, Glen Gabbard and Stuart Twemlow (1984) surmised that, when viewed psychoanalytically, the "being of light" may represent an internalized parent. Mortimer Ostow (1960) and Narcyz Lukianowicz (1958) agreed that the NDE can be explained in part by ego wish fulfillment.

Some social scientists have concluded that NDEs are akin to dreams that seem very real. Dorothy Counts (1983) found that in New Guinea, the culturally structured nature of out-of-body and NDE accounts suggest that both are the product of a state of mind known as hypnagogic sleep. Similarly, Celia Green (1968) argued that certain aspects of NDEs, such as out-of-body experiences and the travel through a tunnel, are very much like the lucid dream phenomenon, where the subject is aware that he or she is dreaming.

The field of sensory deprivation also has application to the neardeath phenomenon. John Lilly (1977) observed that some subjects in sensory deprivation tanks experienced the out-of-body sensation. Even more suggestive is the story of two miners who were trapped underground for six days. The two had hallucinations that included people, a cross, a heavenly garden, and blue lights. The psychiatrists who evaluated these two miners concluded that under conditions as stressful as this, hallucinations serve to address perceived needs (Comer, Madow, and Dixon, 1967).

Psychological explanations of NDEs have raised some very interesting analogies from various aspects of the field. However, none as yet constitute proof that the NDE is caused by one factor or another. There might be some truth in some or all of these explanations, but we have not yet seen any definitive explanation for the whole phenomenon.

In her 1993 book, Dying to Live: Near-Death Experiences, Blackmore rejected metaphysical explanations of the NDE. She agreed that NDE 
accounts were consistent; however, she did not agree that this consistency constituted proof of an afterlife. Blackmore drew upon various aspects of modern science to demonstrate her contention. For example, the joy and peace people experience are a result of "natural opiates released under stress" (p. 261). The "life review is consistent because the endorphins cause random activation and seizures in the temporal lobe and limbic system where memories are organized" (p. 261). Positive transformations in one's life can be attributed to the fact that one is now thinking about death, which in and of itself is enough to make one "less selfish and more concerned for others" (p. 263). Blackmore concluded that the dying brain hypothesis best explained the near-death phenomenon. She went on to write that there really is no "soul" to survive death: "We are simply here and this is how it is. $I$ have no self and ' $I$ ' own nothing. There is no one to die. There is just this moment, and now this and now this" (p. 264).

Blackmore has come up with some interesting possibilities regarding the causes of the NDE, but her work is every bit as conjectural as the metaphysical model. Her book was less a scientific analysis of the phenomenon than a collection of various studies from disparate fields of science that, when put together, give us a physical and psychological alternative to the metaphysical understanding of the NDE. This is really an exposition of Blackmore's beliefs, not anything that approaches scientific proof. Further, as the mystical traditions of the world's religions have shown, one does not have to be near death in order to experience key elements of an NDE. In fact the encounter with the "Divine Light" and the accompanying ecstasy can be achieved by a number of means, none of which has anything to do with a dying brain. I would argue that until we have something more substantial in the way of a purely physical and/or psychological cause for the NDE, metaphysical arguments are still well worth considering.

One point that Blackmore raised that might be worth developing further from a metaphysical point of view is the concept of the self. Blackmore preferred what she defined as the Buddhist position that "neither self nor anything pertaining to self can truly and really be found" (Rahula, 1959, p. 59; cited in Blackmore, 1993, p. 257). Unfortunately, whether intentionally or not, this leaves the impression that Buddhism advocates some form of pure materialism. This is far from the truth. While Buddhism does propose that ultimately the self does not exist, and that the truth beyond the self is nothingness, this does not mean that nothingness is "blackness," or has no intrinsic reality. On the contrary, as we have seen, some scriptures such as 
The Tibetan Book of the Dead (Evans-Wentz, 1957/11 ${ }^{\text {th }}$ century) speak of the "Clear Light of the Void." For Buddhists, the void is vividly real, the ultimate reality, and hardly the cynical nonexistence tacitly referred to by Western materialists.

Ironically, Blackmore's reference to the Buddhist conception of the self can lead us to a new metaphysical understanding of the nature and meaning of life and death. It might be that the soul does not continue to exist indefinitely beyond death, whether in "heaven" or in some form of reincarnation. Buddhist philosophy allows us to see that there might be a state of being beyond this life and even beyond the near-death experience.

\section{A New Focus for the Future}

With modern accounts of near-death experiences and the wealth of world religious traditions at our disposal, we are now in a position to propose refocusing our attention on spiritual experiences themselves, not just specific religious interpretations of them. This is not to minimize or attempt to make redundant the differences between traditions; without differences, human expressions of spirituality would not be nearly as rich. However, the differences are abundant and often readily apparent. The common thread, the truth that binds, is more elusive and difficult to define. The thread is there, though, and this is where humanity desperately needs to direct its efforts now.

This approach is necessary because the modern Western preoccupation with materialism has left the present generation increasingly devoid of spiritual meaning. Material reality appears to be so real, so consistent, whereas spirituality in the form of religion or philosophy changes drastically from tradition to tradition and from person to person. What makes one tradition or spiritual philosophy better than the other? The purely materialistic worldview, on the other hand, does not need to prove or demonstrate the existence of any truth beyond that which we can see, hear, touch, taste, or smell. It is no wonder, then, that such an obvious worldview as materialism has gained so many adherents.

Spiritual worldviews still exist, though, and in many forms. I contend that these persist, and will continue to persist, because of spiritual experiences. Such experiences come in a variety of forms, but typically are enough to transform one's view of reality. The mystical experience, in particular, of which the near-death experience is one 
form, is the one that I will now use to "sew the thread" of a common human spirituality.

Mystics often say that the mystical experience is extremely rare. That might be true, if we expect to find exactly the same experience, let alone exactly the same interpretation of the experience, in every reported instance. Viewed more broadly, however, the mystical experience in all its forms might be much more common than is generally assumed. Mystical experiences range from a feeling of elevated spiritual joy to visions of Divinity to oneness with the universe. In this essay, I have focused more specifically on the mystic encounter with light and ecstasy. This aspect of mysticism is directly parallel to the reports of an encounter with a "being of light" in the near-death experience. This demonstrates that the same experience can be found across cultures and throughout time. It also suggests that with the growing number of reports of near-death experiences, the phenomenon is not as rare as some might believe.

An even more common form of the mystical experience is that of spiritual ecstasy alone. In modern Christian revivalism, the experience of joy in Christ or the Holy Spirit is a cornerstone of the movement. Revivalist, "born-again," or "charismatic" Christians report a depth of religious feeling that has to be considered at some level a form of mystical experience. Given that this form of religious expression is quite common, so too then must be this aspect of the mystical experience. The interpretation of exactly what that experience means for that category of Christian is often, of course, at variance with the interpretation of others who have undergone the same kind of encounter. Nonetheless, reports of the phenomenon are found well beyond the Christian fold. Again this suggests that the experience itself is not so rare; it is more likely the specific interpretations of the experience that make an individual or a movement seem so unique or special.

One of the most common forms of the mystical experience, then, is the joyful encounter with a loving spiritual being, the kind so often reported in various forms of religious revivalism. Related to this, although not quite as common, is the encounter with Divine Light, as I have described. Probably the least common is the complete union of the soul with the Divine. Other phenomena, such as the perceived separation of the soul from the body, might be included as aspects of the mystical experience. These are all part of a journey toward a single end: spiritual communion with the Divine. The vision of spiritual light and the feeling of ecstasy let us know that the Divine not only exists, 
but exists in resplendent and loving glory. Union allows us to catch a glimpse of what might be the final resting place of humanity, the soul's ultimate destination.

This leads us back to the concept of the self, which was brought up by Blackmore. In the final analysis, there might not be an "eternal" human soul, as Blackmore suggested. Becoming truly and fully immersed in the Divine might not leave much room for personal identity. Blackmore argued in favor of a more immediate extinction of the personality, but since she raised Buddhist philosophy in support of her contention that "there is no self," then we should examine that concept in the light of the larger Buddhist tradition. Blackmore was, consciously or otherwise, quoting the views of the Theravada ("the school of the elders") sect of Buddhism, an ancient but minority view in the Buddhist tradition. The majority view is found in Mahayana ("greater vehicle") Buddhism, which also agrees that ultimately there is no "self" as we perceive it in this life. Meanwhile, however, we do have perceptions in this life that not only seem real but that we have to work with, regardless of ultimate reality. One of these present realities is the concept of personal identity. The concept of self is perfectly acceptable as long as we do not make any distinctions between ourselves and other things.

The extinction of the self in Mahayana Buddhism is very much like the identification of Atman and Brahman in the Hindu tradition, and similar to the union of the soul with God in Judaism, Christianity, and Islam. In Mahayana Buddhism, it is perfectly legitimate to worship God or the gods, as this will help draw us closer to the Ultimate Enlightenment. Once we do achieve enlightenment, however, both the gods and the self disappear, because we realize that all is One. Blackmore was therefore making a huge leap to that tenet of Buddhism that holds that ultimately there is no self. This is a far cry from the conviction of the majority stream of Buddhism that says that, as long as we are in this life and not One with the highest reality, the concept of the self is perfectly legitimate. Considerable qualification is needed, then, before we can accept Blackmore's contention that Buddhists would support her claim that there is no soul to survive bodily death.

That being said, Blackmore did raise an interesting challenge to her opponents in the field of near-death studies, because those who have undergone a near-death experience have not been "dead" for very long. What happens after this initial process? Does the perceived "disembodied soul" continue to exist in a separate existence, either in heaven or in hell, forever? If we accept the doctrine of reincarnation, does this 
mean that we are going to be born, die, and be born again forever? Or, as Blackmore and others would have it, do we simply cease to exist the moment after we die?

An analysis of the mystical experience can help us understand the near-death experience and perhaps even reconcile it with the major religious traditions of the world. Even in its most elementary form, the mystical experience is literally awesome, as is the near-death experience. If we can imagine what it would be like to be as awe-struck as the near-death experiencer, it is easy to see why someone might view the experience as an encounter with some spiritual being that is much greater than and separate from oneself, that is, God. On the other hand, one might conclude that since this happened within oneself, then there might just be much more to oneself than previously assumed, even to the point that Divinity resides within oneself.

Those who have a mystical experience while they are members of a given tradition are likely to interpret the experience within the doctrine of the tradition concerned. This often leads to an identification of the experience with the interpretation, such as "God's Holy Spirit has come to me," or "I have experienced nirvana." Unfortunately, too strict an adherence to an all-encompassing interpretation of such a deeply felt experience can lead to fundamentalism, intolerance, and cultism. The field of near-death studies is particularly refreshing in this regard, because its focus is still on the experience itself, and the interpretations generally make reference to the pure experience. Such a focus would be very helpful in breathing new spiritual and intellectual life into religion.

After all, if profound spiritual experiences do not have relevance in religion, than what does? All major religious traditions have plenty of examples of these occurrences, both historically and more than likely even within their current memberships. Further, by looking at the religious experiences of traditions other than one's own, we would see how others could develop different ways of looking at a common spiritual source.

Clearly there are other religious experiences besides mystical ones. Some are downright terrifying, and others visionary, without any relation to the mystical vision. The mystical experience is unique only because the language used to describe it is so similar from tradition to tradition. Near-death experiences are largely consistent with mystical accounts, which speaks well for the continuity of the phenomenon. If we can broaden near-death research to include more fully the religious mystical experience, then we can deepen our understanding of both 
fields. And if we keep both fields focused on the experience itself, then we might come up with new and better interpretations of it.

Meanwhile, recognizing a common human spirituality has great personal and social value. For the individual, this might be the sense of spiritual meaning that so many find lacking in a materialistic society. For society, it might mean removal of the veil of bigotry that has characterized too many religious movements for far too long. Society might grow to appreciate our common spiritual heritage as we share our experiences, while being able to respect the various ways that we interpret them.

\section{References}

Blacher, R. S. (1979). To sleep, perchance to dream .... JAMA: Journal of the American Medical Association, 242, 2291.

Blackmore, S. B. (1988). Visions of the dying brain. New Scientist, 118, 43-46.

Blackmore, S. B. (1993). Ding to live: Near-death experiences. Buffalo, NY: Prometheus.

Brinkley, D., and Perry, P. (1994). Saved by the light: The true story of a man who died twice and the profound revelations he received. New York, NY: Villard.

Brinkley, D., and Perry, P. (1995). At peace in the light. New York, NY: HarperCollins.

Bucke, R. M. (1901). Cosmic Consciousness: A Study in the Evolution of the Human Mind. Philadelphia, PA: Innes.

Burt, C. (1968). Psychology and psychical research: The $17^{\text {th }}$ Frederic W. H. Myers Memorial Lecture. London, England: Society for Psychical Research.

Carr, D. B. (1981). Endorphins at the approach of death. Lancet, 1, 390.

Carr, D. B. (1982). Pathophysiology of stress-induced limbic lobe dysfunction: A hypothesis for NDEs. Anabiosis: The Journal of Near-Death Studies, 2, 75-89.

Comer, N. L., Madow, L., and Dixon, J. J. (1967). Observations of sensory deprivation in life-threatening situations. American Journal of Psychiatry, 124, 164-169.

Counts, D. A. (1983). Near-death and out-of-body experiences in a Melanesian society. Anabiosis: The Journal of Near-Death Studies, 3, 115-135.

Eadie, B. J., and Taylor, C. (1992). Embraced by the light. Placerville, CA: Gold Leaf Press.

Ehrenwald, J. (1978). The ESP experience: A psychiatric validation. New York, NY: Basic Books.

Evans-Wentz, Y. A. (1957). The Tibetan book of the dead. London, England: Oxford University Press. (Original work published $11^{\text {th }}$ century)

Gabbard, G. O., and Twemlow, S. W. (1984). With the eyes of the mind: An empirical analysis of out-of-body states. New York, NY: Praeger.

Green, C. E. (1968). Lucid dreams. Oxford, England: Institute of Psychophysical Research.

Grof, S. (1972). Varieties of transpersonal experience. Journal of Transpersonal Psychology, 4, 45-80.

Grof, S. (1972-73). LSD and the human encounter with death. Voices, 8, 64-77.

Holck, F. H. (1978-79). Life revisited: Parallels in death experiences. Omega, 9, $1-11$.

Huxley, A. (1954). The doors of perception of heaven and hell. New York, NY: Harper and Row. 
James, W. (1902). The varieties of religious experience: A study in human nature. New York, NY: Longman, Green.

Lilly, J. C. (1977). The deep self: Profound relaxation in the tank isolation technique. New York, NY: Simon and Schuster.

Lowental, U. (1981). Dying, regression, and the death instinct. Psychoanalytic Review, $68,363-370$.

Lukianowicz, N. (1958). Autoscopic phenomena. AMA Archives of Neurology and Psychiatry, 80, 199-220.

Moody, R. A. (1975). Life after life. Covington, GA: Mockingbird Books.

Moody. R. A. (1977). Reflections on life after life. St. Simon's Island, GA: Mockingbird Books.

Morse, M. L., and Perry, P. (1990). Closer to the light: Learning from the near-death experiences of children. New York, NY: Villard.

Noyes, R. (1979). Near-death experiences: Their interpretation and significance. In Kastenbaum, R. (ed.), Between life and death (pp. 73-88). New York, NY: Springer.

Ostow, M. (1960). The metapsychology of autoscopic phenomena. International Journal of Psychoanalysis, 41, 619-625.

Pahnke, W. N. (1969). LSD-assisted psychotherapy with terminal cancer patients. Current Psychiatric Therapies, 9, 144-152.

Pahnke, W. N., and Richards, W. A. (1966). Implications of LSD and experimental mysticism. Journal of Religion and Health, 5, 175-208.

Provonsha, J. W. (1981, January). Life after life: Do some people really die and come back to life? Life and Health, pp. 14-15.

Rahula, W. (1959). What the Buddha taught. London, England: Gordon Fraser.

Richards, W., Grof, S., Goodman, L., and Kurland, A. (1972). LSD-assisted psychotherapy and the human encounter with death. Journal of Transpersonal Psychology, 4, 121-150.

Ring, K. (1980). Life at death: A scientific investigation of the near-death experience. New York, NY: Coward, McCann and Geoghegan.

Ring, K. (1988). Paradise is paradise: Reflections on psychedelic drugs, mystical experience, and the near-death experience. Journal of Near-Death Studies, 6, $138-148$.

Rodin, E. A. (1980). The reality of death experiences: A personal perspective. Journal of Nervous and Mental Disease, 168, 259-263.

Rogo, D. S. (1984). Ketamine and the near-death experience. Anabiosis: The Journal of Near-Death Studies, 4, 87-96.

Sabom, M. B. (1980a). Commentary on "The reality of death experiences" by Ernst Rodin. Journal of Nervous and Mental Disease, 168, 266-267.

Sabom, M. B. (1980b). The near-death experience [Letter]. JAMA: Journal of the American Medical Association, 244, 29-30.

Schnaper, N. (1980). Comments germane to the paper entitled "The reality of death experiences" by Ernst Rodin. Journal of Nervous and Mental Disease, 168, 268-270.

Sherley-Price, L. (Trans.) (1968). Bede's history of the English church and people. New York, NY: Penguin. (Original work published $8^{\text {th }}$ century.)

Siegel, R. (1980). The psychology of life after death. American Psychologist, 75, 911-931.

Smith, H. (1964). Do drugs have religious import? Journal of Philosophy, 41, 517-530.

Stevenson, I. (1980). Comments on "The reality of death experiences: A personal perspective." Journal of Nervous and Mental Disease, 168, 271-272.

Tolstoy, L. (1981). The death of Ivan Ilyich. New York, NY: Penguin. (Original work published 1886 in Russian.)

Watts, A. (1973). In my own way. New York, NY: Vintage.

Zaleski, C. (1987). Otherworld journeys: Accounts of near-death experience in medieval and modern times. New York, NY: Oxford University Press. 